\title{
Guaraná (Paullinia cupana Kunth), marapuama (Ptychopetalum olacoides Benth.), genciana (Gentiana lutea L.), quassia (Quassia amara L.) e suas propriedades: uma
}

\section{breve revisão}

\author{
Guarana (Paullinia cupana Kunth), marapuama (Ptychopetalum olacoides Benth.), gentian (Gentiana \\ lutea L.), quassia (Quassia amara L.) and their properties: a brief review \\ Guaraná (Paullinia cupana Kunth), muira puama (Ptychopetalum olacoides Benth.), genciana \\ (Gentiana lutea L.), quassia (Quassia amara L.) y sus propiedades: una breve revisión
}

Recebido: 09/12/2021 | Revisado: 18/12/2021 | Aceito: 21/01/2022 | Publicado: 23/01/2022
Fernando Augusto Morgado Ferreira ORCID: https://orcid.org/0000-0001-6259-4156 Universidade Federal do Pará, Brasil E-mail: soberanabel@gmail.com
Bárbara Bragança Ferreira ORCID: https://orcid.org/0000-0002-7759-1430 Universidade Federal do Pará, Brasil
E-mail: barbara.bragancaferreira@gmail.com
Vitor Augusto Nascimento Bragança ORCID: https://orcid.org/0000-0003-2772-5717 Universidade Federal do Pará, Brasil E-mail: vanbraganca@gmail.com
Consulelo Lúcia Sousa de Lima ORCID: https://orcid.org/0000-0001-9432-8637 Universidade Federal do Pará, Brasil E-mail: sousa@ufpa.br
Davi do Socorro Barros Brasil ORCID: https://orcid.org/0000-0002-1461-7306 Universidade Federal do Pará, Brasil E-mail: davibb@ufpa.br

\begin{abstract}
Resumo
A descoberta e o manejo de recursos naturais são essenciais no processo de desenvolvimento social. Por milhares de anos, a humanidade tem se utilizado de plantas com os mais diversos intuitos, como, por exemplo, para o alívio e a cura de enfermidades. A diversidade florística brasileira também possibilitou que as comunidades nativas adquirissem e desenvolvessem conhecimentos associados ao uso de inúmeros vegetais. Esta breve revisão da literatura tem por objetivo fazer um levantamento das propriedades de quatro espécies vegetais - guaraná (Paullinia cupana Kunth), marapuama (Ptychopetalum olacoides Benth.), genciana (Gentiana lutea L.), quassia (Quassia amara L.) - amplamente utilizadas pelos nativos da região amazônica, especialmente devido as suas propriedades terapêuticas. Destaca-se, por fim, a existência de grande potencial para o aprofundamento de pesquisas nas espécies vegetais revisadas, principalmente no que se refere ao uso fitoterápico - uma vez que essas tem mostrado, de acordo com fontes consultadas, auxiliar nos mais diversos quadros de saúde.
\end{abstract}

Palavras-chave: Guaraná; Marapuama; Genciana; Quassia; Fitoterapia.

\begin{abstract}
The discovery and management of natural resources are essential in the social development process. For thousand years, humanity has been using plants for the most diverse purposes, such as the relief and cure of illnesses. The Brazilian floristic diversity also enabled native communities to acquire and to develop knowledge associated with the usage of numerous plants. This brief literature review aims to survey the properties of four plant species - guarana (Paullinia cupana Kunth), marapuama (Ptychopetalum olacoides Benth.), gentian (Gentiana lutea L.), quassia (Quassia amara L.) - widely used by natives of the Amazon region, especially due to their therapeutic properties. Finally, it is possible to highlight the existence of great potential for furthering research on the revised plant species, especially regard to herbal medicine usage - once these have shown, according to consulted sources, to assist in the most diverse health conditions.
\end{abstract}

Keywords: Guarana; Marapuama; Gentian; Quassia; Phytotherapy. 


\section{Resumen}

El descubrimiento y la gestión de los recursos naturales son fundamentales en el proceso de desarrollo social. Durante miles de años, la humanidad ha estado utilizando plantas para los propósitos más diversos, como el alivio y la cura de enfermedades. La diversidad florística brasileña también hizo posible que las comunidades nativas adquirieran y desarrollaran conocimientos asociados al uso de numerosas plantas. Esta breve revisión de la literatura tiene como objetivo estudiar las propiedades de cuatro especies de plantas: guaraná (Paullinia cupana Kunth), muira puama (Ptychopetalum olacoides Benth.), genciana (Gentiana lutea L.), quassia (Quassia amara L.), ampliamente utilizada por los nativos de la región amazónica, especialmente por sus propiedades terapéuticas. Finalmente, es posible destacar la existencia de un gran potencial para avanzar en la investigación sobre las especies de plantas revisadas, especialmente en lo que respecta al uso de medicamentos a base de hierbas, una vez que estos han demostrado, según las fuentes consultadas, ayudar en las más diversas condiciones de salud.

Palabras clave: Guaraná; Muira puama; Genciana; Quassia; Medicina herbaria.

\section{Introdução}

A descoberta e o manejo de recursos naturais são essenciais no processo de desenvolvimento social. Os elementos obtidos por extração na natureza apresentam grande versatilidade, possuindo aplicações concretas em diversos setores das sociedades antigas e contemporâneas (Firmo, et al., 2011; Khan, 2014). Nesse contexto, uma das matérias-primas mais procuradas para a aquisição de novos conhecimentos são as espécies vegetais.

As plantas podem ter, de maneira geral, um aproveitamento quase que total - desde as estruturas físicas como o lenho até os metabólitos produzidos durante seu processo de desenvolvimento (Derkach \& Tarasenko, 2021; Silva, et al., 2017).

Por milhares de anos, a humanidade tem se utilizado de plantas para aliviar e curar enfermidades: desde 4.000 a.C., existem registros sobre a utilização de espécies da flora no tratamento de doenças (Duarte, 2006). As plantas medicinais podem ser consideradas precursores de diversos medicamentos modernos e são úteis para os cuidados de saúde primários (Bhattacharjee, et al., 2006).

Até meados do século XIX, os recursos terapêuticos eram constituídos predominantemente por plantas e extratos vegetais, o que pode ser ilustrado pelas farmacopeias da época. Já no início do século XX, esses recursos começaram a ser estudados como instrumento científico e se estabeleceu paulatinamente a tendência da utilização das substâncias ativas isoladas, os chamados "princípios ativos" (Schenkel, et al., 2004).

Nesse contexto, o Brasil se destaca no cenário global como o maior banco de biodiversidade genética, contemplando aproximadamente $20 \%$ de toda a diversidade animal e vegetal presente no planeta (Yamaguchi \& Souza, 2020) - fator que coloca o país em uma posição privilegiada de detentor e fornecedor de recursos naturais (Basso, et al., 2005).

A diversidade florística brasileira também possibilitou que as comunidades nativas adquirissem e desenvolvessem conhecimentos associados ao uso desses vegetais para o atendimento de suas necessidades, manutenção da saúde e tratamento de doenças, fomentando, assim, o conhecimento etnobotânico por populações para o uso direcionado das espécies utilizadas (Aftab \& Hakeem, 2021; Kaur \& Ahmed, 2021; Lima, et al., 2016).

Atualmente, os benefícios oriundos dos metabólitos de espécies vegetais tem sido utilizados não apenas com finalidade curativa, mas ganhado considerável destaque como um recurso preventivo (Aftab \& Hakeem, 2021). Muitas espécies tem despertado o interesse das indústrias, sobretudo as encontradas no ambiente amazônico, por conta de suas potenciais influências sobre, por exemplo, a fadiga e a indisposição - ambas características do estilo de vida moderno (Sharma, et al., 2021).

Para população amazônica, quatro espécies podem ser destacadas entre as tradicionalmente utilizadas: guaraná (Paullinia cupana Kunth), marapuama (Ptychopetalum olacoides Benth.), genciana (Gentiana lutea L.) e quassia lenho (Quassia amara L.). Este trabalho se propôs a realizar uma breve revisão sobre cada espécie apresentada e suas propriedades gerais. 


\section{Métodos}

O trabalho consiste em uma revisão bibliográfica simples que teve como principal enfoque fazer um levantamento das propriedades de quatro espécies vegetais amazônicas amplamente utilizadas pelos nativos por suas propriedades terapêuticas.

Todas as informações utilizadas foram obtidas através da análise de artigos científicos, livros, documentos governamentais e pesquisas nas bases bibliográficas Google Scholar, LILACS e SCIELO, seguindo o critério de seleção sistemática demostrado na Figura 1. O espaço temporal para a pesquisa bibliográfica contemplou os anos de 2002 a 2018, incluindo também teses e dissertações.

Para a realização da revisão narrativa proposta, foram utilizados termos em português e inglês como: Etnobotânica (Ethnobotany), conhecimento tradicional (traditional knowledge), Propriedades biológicas e terapêuticas das espécies (Biological and therapeutic properties).

Figura 1. Etapas da pesquisa.

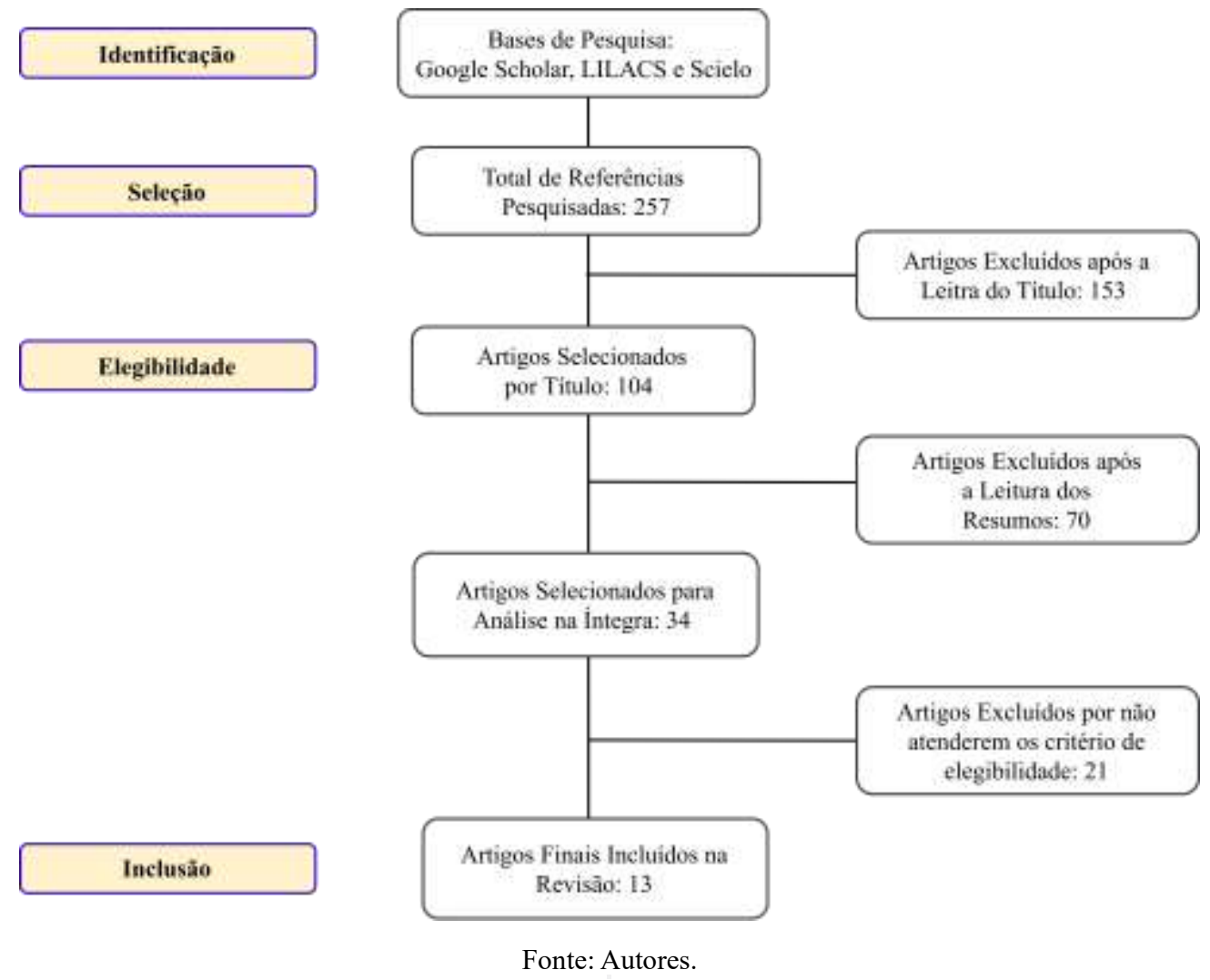

Trabalhos incompletos e/ou indisponíveis integralmente, manuscritos sem informações sobre autoria e/ou origem foram excluídos. Os resultados desse trabalho foram expressos de maneira descritiva, tendo como base o objetivo e a sintetização dos dados obtidos através da análise dos artigos finais selecionados no Quadro 1. 


\section{Quadro 1: Artigos Selecionados.}

\begin{tabular}{|c|c|c|c|}
\hline Título & Autor / Ano & Objetivos & Síntese dos dados \\
\hline $\begin{array}{l}\text { Guarana powder polysa } \\
\text { ccharides: Characterisati } \\
\text { on and evaluation of } \\
\text { the antioxidant activity } \\
\text { of a pectic fraction }\end{array}$ & $\begin{array}{c}\text { Dalonso, N. \& } \\
\text { Petkowicz, C. L. O. / } \\
2012\end{array}$ & $\begin{array}{l}\text { Avaliação dos polissacarídeos presentes no } \\
\text { guaraná, para verificação de potencial } \\
\text { antioxidante assim como outras substâncias } \\
\text { presentes no vegetal, por exemplo, os } \\
\text { componentes pécticos. }\end{array}$ & $\begin{array}{l}\text { O pó de guaraná apresenta amido, que é responsável por suas } \\
\text { propriedades energéticas, caracterizando-o como um eficiente } \\
\text { suplemento nutricional. Esta espécie também contém fibras } \\
\text { alimentares, incluindo polissacarídeos pécticos e } \\
\text { hemiceluloses com função energética. A presença de } \\
\text { polissacarídeos pécticos exibiu potenciais atividades } \\
\text { antioxidantes, que foram comprovadas pelos testes de } \\
\text { sequestro de radical hidroxila e de radical DPPH. Assim, é } \\
\text { indicado a ingestão diária do pó de guaraná, como um } \\
\text { suplemento eficiente e com consideráveis benefícios ao } \\
\text { organismo. }\end{array}$ \\
\hline
\end{tabular}

A rapid simultaneous determination of methylxanthines and proanthocyanidins in

Brazilian guaraná

(Paullinia cupana Kunth.)

Guaraná (Paullinia cupana) seeds: Selective supercritical extraction of phenolic compounds

Antioxidant Capacity and In Vitro Prevention of Dental Plaque

Formation by Extracts and Condensed Tannins of Paullinia cupana.

Estudo Fitoquímico e de Atividade

Antimicrobiana de

Ptychopetalum

Olacoides Bentham.

Antioxidant activities of Ptychopetalum olacoides

("muirapuama") in mice brain

Novel NGF-potentiating diterpenoids from a Brazilian medicinal plant, Ptychopetalum olacoides

Gentiana lutea Linn. (Yellow Gentian): A comprehensive review
Machado, K. N.; Freitas, O objetivo do presente estudo é desenvolver e A

A. A.; Cunha, L. H: Faraco, A. A. G.; Pádua, R. M.; Braga, F. C.;

Vianna-Soares, C. D. Castilho, R. H. / 2018 validar um método rápido, simples e não possibilita a identificação dos componentes biológicos do trabalhoso para a quantificação simultânea de guaraná. Essas informações são importantes para o duas classes diferentes de substâncias (ou seja, desenvolvimento de métodos extrativos que viabilizem o metilxantinas e taninos): teobromina (TB), aproveitamento dos compostos observados e suas propriedades teofilina (TF), cafeína (CAF), catequina (CT), nutricionais e terapêuticas, como estimulante, fortalecimento epicatequina (ECT) e procianidinas A2 e B2 imunológico e atividade antioxidante.

(A2, B2) em pó de semente de guaraná por RPHPLC-UV/PDA.

Marques, L. L. M.; $\quad$ A sugestão de métodos mais eficientes de A utilização de metodologias estatísticas eficientes possibilita Panizzon, G. P.; Aguiar, extratos de sementes de P. cupana por meio de dados instrutivos que são utilizados para a realização de B. A. A.; Simionato, OAD (Orthogonal Array Design) e a processos extrativos utilizando recursos mínimos e mantendo A.S.; Cardozo-Filho, L.; investigação dos efeitos da temperatura, as propriedades dos metabólitos do guaraná, a qualidade e Andrade, G.; Oliveira, A. G.; Guedes, T. A.; Mello, J. C. P. / 2016 pressão, tempo de extração e modificadores evitando contaminações por microrganismos externos. para desenvolver condições ótimas de extração.

Yamaguti-Sasaki, E. Y; Descrever o monitoramento do teor de tanino A avaliação química das sementes do guaraná identificou Ito, L. A.; Canteli, V. C. das sementes de guaraná e o isolamento de compostos que atuam em processos antioxidantes e D.; Ushirobira, T. M. A.; taninos condensados desta espécie, além de fisiológicos dos organismos (estimulante e imunoestimulante).

Ueda-Nakamura, T.; outros isolados. Determinação da atividade Além disso, a avaliação in vitro das frações semipurificadas Filho, B. P. D.; $\quad$ antioxidante e análise de forma preliminar do apresentou potencial antimicrobiano contra placas bacterianas Nakamura, C. V.; Mello, potencial antibacteriano contra Streptococcus como as produzidas por Streptococcus mutans.

J. C. P. / 2007 mutans dos diferentes extratos (bruto-EBPC e aquoso-AqE) e frações semi-purificadas (EPA e EPB).

Montrucchio, P. D. \& Miguel, O. G. / 2002

Análise Fitoquímica das estruturas presentes no lenho da espécie Ptychopetalum olacoides Bentham.

Siqueira, I. R.;

O objetivo deste estudo foi verificar o efeito Foshesatto, C.; Torres. antioxidante in vivo do POEE (Extrato L. S.; Silva, A. L.; Nunes, D. S.;

Elisabetsky, E.; Netto, C. A. $/ 2007$

Tang, W.; Kubo, M.; Harada, K.; Hioki, H.; Fukuyama, Y. / 2009.

Relatar as estruturas e atividade Alguns diterpenóides encontrados em $P$. olacoides potencializadora de NGF (Fator de apresentaram atividades capazes de estimular o crescimento de Crescimento do Nervo) presente em uma planta neuritos em células PC12, apresentando potencial para o brasileira (Ptychopetalum olacoides) em desenvolvimento de drogas para o tratamento de doenças células PC12 e sua relação estrutura-atividade. neurodegenerativas e crônico-degenerativas do sistema nervoso.

Prakash, O.; Singh, R.; Apresentar as características gerais, A revisão da literatura feita pelos autores mostrou que a espécie Kumar, S.; Srivastava, propriedades medicinais e aplicabilidade ainda apresenta elevada aplicação para procedimentos S.; Ved, A. / 2017 terapêutica dos principais metabólitos da G. tradicionais, além de metabólitos e propriedades terapêuticas $\begin{array}{ll}\text { lutea. } & \text { significativas. Essas características colocam a G. lutea como }\end{array}$ uma espécie em potencial para prevenção e tratamento de algumas enfermidades e determinadas condições de saúde. 
Medicinal, biological and phytochemical properties of Gentiana species

Mirzaee, F.; Hosseinni, Apresentar e descrever alguns potenciais Informações de origem tradicional sobre as propriedades A.; Jouybari, H. B.; características dos compostos bioativos medicinais de espécies do gênero de Gentiana. Diferentes Davoodi, A.; Azadbakht, presentes na espécie, suas aplicações na cultura formas de preparo são utilizadas para o tratamento de variados A./2017 tradicional e seus usos na medicina popular, sintomas e prevenção de enfermidades mais corriqueiras destacando a função medicinal dos glicosídeos relacionadas a infecções, prevenção contra intoxicação, irinóides presentes na espécie. capacidade anti-inflamatória e analgesia de sintomas menstruais. Essas propriedades colocam o gênero como potencial recurso para o desenvolvimento de novos fármacos de origem natural.

Phytochemistry and Pharmacological Activities of the Genus Gentiana

(Gentianaceae)

Anatomia Foliar de Quassia amara L. (Simaroubaceae), uma Espécie Medicinal e Inseticida
Therapeutic Evaluation of Quassia amara Linn. A Critical Review

Evaluation of the analgesic and antiedematogenic activities of Quassia amara bark extract
Pan, Y.; Zhao, Y. L.; Zhang, J.; Li, W. Y.; Wang, Y. Z. / 2016

Macedo, E. G.; Neto, O. R. / 2005 Potiguara, R. C. V.;

Resumir o conhecimento fitoquímico e Muitas espécies de Gentiana são boas fontes para pesquisas farmacológico para espécies do gênero químicas e farmacêuticas devido a sua rica quantidade de Gentiana, atualizar os últimos dados iridóides, flavonóides e triterpenóides. Os resultados ilustram publicados e discutir vários aspetos a diversidade química e o valor das plantas do gênero Gentiana promissores para a pesquisa deste gênero. como potenciais fontes de novos medicamentos para prevenção e tratamento de hepatite, artrite reumática, hipertensão, etc.

Estudos da anatomia foliar como um Algumas características peculiares à espécie estudada foram complemento para o entendimento biológico da identificadas, tais como: a presença de esclereídeos filiformes espécie, além de contribuir para informações distribuídos em todas as direções no mesofilo, dando-lhe taxonômicas de identificação, sendo um consistência e proteção, tricomas glandulares ovalados aspecto importante para uma família botânica divididos em três partes: cabeça, pescoço e pé; tricomas numerosa como a Simaroubaceae. filiformes com células basais secretoras e tricomas simples onde todo o corpo libera óleo.Essas características se mostram úteis para o processo de identificação taxonômica da espécie.

Remya, E. \& Goyal, M. Revisar criticamente o perfil farmacológico e Farmacologicamente, o extrato de Quassia amara provou ter / 2017 clínico de Quassia amara Linn. propriedades antidiabéticas, antimaláricas, antiulcerogênicas, antinociceptivas, sedativas, relaxantes musculares e psicomiméticas.

Toma, W.; Gracioso, J. Avaliar os possíveis efeitos Os resultados obtidos mostraram que, os mecanismos ainda

S.; Himura-Lima, C. A.; antiedematogênicos, antinociceptivos e/ou que sejam incertos, aparentemente estão relacionados às Andrade, F. D. P.; $\quad$ sedativos de quatro diferentes extratos obtidos atividades sedativas e relaxantes musculares ou Vilegas, W. Souza Brito, da casca de Quassia amara. psicomiméticas do extrato hexano da planta. A. R. M. / 2003

Fonte: Autores.

\section{Resultados e Discussão}

\subsection{Guaraná (Paullinia cupana Kunth)}

O guaraná (Paullinia cupana Kunth) é fruto do guaranazeiro, uma planta nativa da região Amazônica, de baixo crescimento e cultivada exclusivamente no Brasil. É uma espécie vegetal arbustiva e trepadeira, pertencentes à família das Sapindáceas, cujo nome provém do termo indígena "wara 'ná", que significa árvore que sobe apoiada em outra (Araújo, et al., 2010; Dalonso \& de Oliveira Petkowicz, 2012; Mehr, et al., 1996).

O gênero Paullinia compreende cerca de 180 espécies distribuídas pelo continente americano, sendo duas destas, localizadas na região da floresta Amazônica e diferem-se quanto à forma, tamanho e cor do fruto, além da localização geográfica, sendo elas: Paullinia cupana Mart var. 'typica', distribuindo-se na Venezuela e Colômbia e Paullinia cupana Mart var. 'sorbilis', encontrada somente no Brasil, a qual é econômica e comercialmente utilizada e mais estudada (Tricaud, et al., 2016).

Guaraná, também conhecido por guaraná-da-amazônia, guaranaina, guaraná, uarana ou narana, é uma fruta esférica, enegrecida e brilhante, assumindo uma forma de cápsula com um a três folhetos, dentro do qual existe apenas uma semente. Quando maduro, apresenta casca de coloração predominante vermelho e laranja. Depois de alcançar a plena maturidade, abre parcialmente expondo as sementes. O pericarpo é marrom-escuro, parcialmente coberto por uma substância branca (arilo), servindo para a dispersão do fruto da semente (Kuskoski, et al., 2005).

Devido ao alto potencial desta planta em referência às suas características medicinais e alimentares/nutricionais como propriedade estimulantes, afrodisíacas e cicatrizantes (Marques, et al., 2016), além da rentabilidade e importância econômica e social no Brasil, o guaraná tornou-se uma importante matéria-prima, sendo responsável por aproximadamente 70\% da produção de refrigerantes e bebidas energéticas (Machado, et al., 2018; SUFRAMA, 2013), o restante é comercializado principalmente 
em drogarias por meio de formulações em pó, cápsulas e comprimidos, as vezes também misturados a outros ingredientes (Machado, et al., 2018).

O Brasil é o maior produtor de guaraná do mundo, em cultivos racionais e sistemáticos com uma área plantada de 15.182 hectares e uma produção de 3658 toneladas em 2015 (IBGE (Instituto Brasileiro de Geografia e Estatística), 2016; Marques et al., 2016). Os principais estados produtores são Bahia, Amazonas, Mato Grosso, Acre e Pará (Silva, 2015; Tricaud, et al., 2016). Seu cultivo data da época pré-colombiana, quando era produzido e consumido por diversas tribos indígenas, dentre as quais Maués e Andiras, localizados no "baixo Amazonas" (SUFRAMA, 2013), onde os primeiros relatos indicam que os nativos de Maués utilizavam a bebida antes de irem às lutas e em longas caminhadas para aumentar a resistência à sede, ao calor e à fadiga (Atroch, 2009).

O guaraná comercial pode ser encontrado de quatro formas diferentes: guaraná em rama (grão torrado); guaraná em bastão (pasta do grão torrado, triturado, pilado e misturado com água em forma de bastão); guaraná em pó (grão torrado e moído); xaropes e essências, sendo esta a forma mais disponível no mercado (EMBRAPA, 2005; Majhenič, et al., 2007). A parte do guaraná mais utilizada comercialmente são as sementes secas, devido ao seu grande teor de cafeína (Machado et al., 2018).

\subsubsection{Composição fitoquímica do guaraná (Paullinia cupana Kunth)}

O guaraná é um dos vegetais mais ricos em cafeína, considerada a xantina mais consumida mundialmente, atingindo cerca de $80 \%$ da população mundial (Ogawa \& Ueki, 2007). A concentração média deste composto representa cerca de 3 a $6 \%$ do peso do fruto (Martins, 2010; Yamaguti-Sasaki, et al., 2007; Yonekura, et al., 2016).

A semente do guaraná contém concentrações expressivas de compostos fenólicos, estes com comprovada atividade antioxidante (Martins, 2010). É possível encontrar uma alta porcentagem (3,2 - 7\%) de cafeína (1,3,7 trimetilxantina) (Dalonso \& de Oliveira Petkowicz, 2012; Heckman, et al., 2010), sendo esta, presente em mais de 60 espécies de plantas, como por exemplo no guaraná, em cafés, chás, além de chocolates, cacau, bebidas derivadas de cola e diversos medicamentos (Harland, 2000; Yamaguti-Sasaki, et al., 2007). A cafeína é ingrediente ativo do guaraná, e é amplamente responsável por sua característica estimulante (Machado, et al., 2018).

A semente do guaraná apresenta diversos compostos bioativos em sua composição tais como metilxantinas, em maior concentrações a cafeína, além de proporções menores de outros alcaloides purínicos como a teobromina (3,7- dimetilxantina) e a teofilina (1,3-dimetilxantina); também contém taninos (catequinas, epicatequinas e proantocianidinas), saponinas e vestígios de outros compostos (Bittencourt et al., 2014; Lima, et al., 2017; Lima, et al., 2019; Lima, et al., 2018; Marques et al., 2016).

\subsubsection{Propriedades terapêuticas do guaraná (Paullinia cupana Kunth)}

O guaraná (Paullinia cupana Kunth, Sapindaceae) é popularmente usado na medicina como estimulante do sistema nervoso central (Majhenič, et al., 2007) e do sistema cardiovascular para tratar o estresse físico e mental (Henman, 1982; Machado, et al., 2018; Yamaguti-Sasaki, et al., 2007) melhorando a disposição e reduzindo a fadiga (Webb, 2008).

A partir da década de 90, as investigações foram intensificadas a respeito de uma série de propriedades funcionais, sendo indicadas características cardiotônica e cardioprotetora, adipogênese (Lima, et al., 2017), atividade antiplaquetária (Costa Krewer, et al., 2011; Harrold, et al., 2013; Portella, et al., 2013; Tfouni, et al., 2007). Por exemplo, o guaraná em pó é utilizado popularmente como estimulante devido às concentrações de cafeína em sua composição, além de propriedades antidiarréicas, analgésicas, antipiréticas, no tratamento de enxaqueca e alegações afrodisíacas (Henman, 1982; Majhenič, et al., 2007; Marques et al., 2016), ação anticancerígena e quimioprofilática da carcinogênese (Espinola, et al., 1997; Fukumasu, et al., 2008), antimicrobianas e antioxidantes (Basile et al., 2005; Dalonso \& de Oliveira Petkowicz, 2012; Yamaguti-Sasaki, et al., 2007), antiproliferativa (Hertz, et al., 2015), energética e ação termogênica (Andersen \& Fogh, 2001), antidepressiva (Audi \& Mello, 
2000) e qualidades ansiolíticas (Rangel, et al., 2013). Além de utilização na prevenção de doenças orais contra Streptococcus mutans (Yamaguti-Sasaki, et al., 2007), bem como mecanismo para reduzir os efeitos oxidativos e distúrbios metabólicos no organismo (Marques, et al., 2016; Portella, et al., 2013).

Além dessas propriedades, que podem ser atribuídas à presença de cafeína e outros alcaloides, outras propriedades medicinais das sementes de guaraná foram investigadas, como a inibição da agregação plaquetária in vitro e in vivo (Bydlowski, et al., 1988), a proteção contra lesões gástricas induzidas por etanol e indometacina in vivo (Campos, et al., 2003), atividade antigenotóxica in vivo (Fukumasu et al., 2008). Foi observada a capacidade antioxidante in vivo do guaraná em pó, em dose referida a $3 \mathrm{~g} / 200 \mathrm{ml}$ de água, resultando na diminuição do tempo de concentração (lag time) da oxidação de LDL, além da proteção de DNA à ação dos radicais livres em participantes com sobrepeso e obesidade (Martins, 2010).

Bittencourt, et al., (2014) realizou um estudo com células e concluíram que o guaraná exerce efeitos antioxidantes no metabolismo do oxido nítrico (no), principalmente quando a concentração deste está elevado. O efeito antidepressivo foi avaliado com resultados promissores e com efeito benéfico sobre a cognição, sem alteração da atividade locomotora. $\mathrm{O}$ extrato semipurificado do guaraná também mostra um efeito panicolítico (a uma dose de $8 \mathrm{mg} / \mathrm{kg}$ ) (Otobone, et al., 2005; Roncon, et al., 2011; Roncon, et al., 2009).

Haskell, et al., (2007) confirmaram que o guaraná pode trazer benefícios ao desempenho cognitivo e ao humor em adultos jovens. Esse estudo testou 4 diferentes doses de extrato de guaraná - 37,5; 75; 150 e 300mg -, sendo que o nível de alerta aumentou conforme o aumento da dose, entretanto os resultados cognitivos de forma geral tiveram desempenho melhor com as duas doses mais baixas.

Um estudo realizado por (Lima, et al., 2005), avaliou o efeito da suplementação de guaraná no período de 14 dias, sobre aspectos do metabolismo lipídico em ratos sedentários e treinados. Para isolar o efeito da cafeína de outros componentes do guaraná, foram adotadas duas doses diferentes de extrato integral (G1-0.130 g/ kg; G2-0.325 g / kg) ou extrato descafeinado. O grupo que não recebeu nenhum dos extratos ganhou mais peso, sendo que os que receberam a maior concentração de extrato obtiveram menor ganho de gordura. As alterações no metabolismo lipídico de ratos suplementados relatados estão associadas ao teor de metilxantina do guaraná.

Investigações experimentais sugeriram que o consumo de guaraná (Paullinia cupana) está associado a uma menor prevalência de doenças metabólicas cardiovasculares e tem efeitos positivos sobre o metabolismo lipídico, principalmente relacionado aos níveis de lipoproteína de baixa densidade (LDL), sendo a oxidação do LDL colesterol um evento inicial importante no desenvolvimento da aterosclerose.

O guaraná apresenta, semelhante a outros alimentos ricos em cafeína e catequinas, como o chá verde (Camellia sinensis), por exemplo, o qual já foi bem estudado pela literatura, efeito sobre a oxidação do LDL, o que poderia explicar parcialmente os efeitos protetores em doenças cardiometabólicas (Velayutham, et al., 2008).

\subsection{Marapuama (Ptychopetalum olacoides Benth.)}

A marapuama, Ptychopetalum olacoides Benth, é uma planta pertencente à família Olacaceae. Formada por 27 gêneros e 180 espécies, são árvores, arbustos ou lianas lenhosas, em geral hemiparasitas, caracterizada por folhas simples, alternadas, de margem inteira e sem estípulas (Vicentini \& Rossi, 1999).

A espécie, Ptychopetalum olacoides Benth, é uma árvore nativa das florestas tropicais da Bacia Amazônica, sobretudo do Brasil e Guiana Francesa. Cresce em solos úmidos e com sombra, tolera temperaturas mínimas de $15^{\circ} \mathrm{C}$, o que a torna imprópria em outras regiões (Alonso, 2007; Vicentini \& Rossi, 1999). 
Popularmente conhecida como muira puama, mirantã, mairantã, marapuã, mirirapuama, muirapama, muiratã, pauhomem e murapuama, o termo muira em língua indígena significa madeira e puama poderoso (Alonso, 2007; Corrêa, et al., 1998; Montrucchio, et al,, 2002).

Do gênero Ptychopetalum, apenas duas das dez espécies conhecidas são encontradas no Brasil: $P$. olacoides e $P$. uncinatum, ambas na região amazônica.

De acordo com Silva (1925), a Ptychopetalum olacoides é uma árvore de ramos alternos, delgados, cilíndricos e glabros, com os ramos mais novos subangulosos, levemente sulcados longitudinalmente e em geral um tanto flexuosos.

Os relatos de uso da marapuama datam do início do século XX. As primeiras observações do seu uso foram feitas entre os índios da região amazônica, os quais utilizavam primariamente as raízes das plantas novas, como afrodisíaco, tônico e estimulante geral (Júnior, 1981).

No Brasil, os galhos da marapuama são utilizados, na forma de pó ou extratos, nas mais diversas formas farmacêuticas tais como cápsulas, comprimidos, soluções orais, e mesmo na forma de tinturas ou extratos fluidos. Às vezes, a marapuama é usada isoladamente, mas costuma ser associada, na maioria das formulações, com outras plantas conhecidas como estimulantes, como por exemplo, o guaraná e a catuaba (Montrucchio, 2001).

\subsubsection{Composição fitoquímica da marapuama (Ptychopetalum olacoides Benth.)}

Dentre todos os trabalhos publicados, desde 1907 até os dias atuais, referentes à composição química da marapuama, a maioria se reporta às raízes da planta. Weigel (1907) escreve que os principais constituintes são um óleo etéreo e um princípio cristalino amargo, solúvel em água quente mas que recristaliza em água fria, o qual o autor não nomeia. Griebel (1912) descreve em seu artigo um método para detectar o "princípio afrodisíaco" da marapuama, ainda tratada como Liriosma ovata, por uma reação de fluorescência. Embora o autor não cite o tipo químico desta substância, o sistema de extração, por diferenciação em meio ácido e básico leva-nos a acreditar ser esta substância de algum grupo alcaloídico.

Silva (1925) ainda nos dá as características da marapuama como sendo insolúvel na água fria e solúvel na água fervente, donde se separa pelo resfriamento; dissolve-se facilmente no álcool, no éter e na água acidulada; forma um precipitado branco com o reativo de Mayer (cloreto mercúrico e iodeto de potássio), precipitado amarelo com o trinitrofenol e precipitado pardoavermelhado com o soluto iodoiodetado.

Pankow e Auterhoff (1969) relatam a presença dos ácidos araquídico, behênico, lignocérico, uncosanóico, tricosanóico e pentacosanóico. Os autores relatam a presença do lupeol como principal componente da fração lipofílica da marapuama.

Toyota (1979) descreve a presença de sete ácidos graxos livres de cadeia longa, além da presença de cumarinas. Forgacs (1983) publica um estudo fitoquímico de 18 plantas da Guiana Francesa, incluindo a Ptychopetalum olacoides. Neste estudo os autores relatam a presença de alcalóides, saponinas, taninos e leucoantocianidinas.

Em trabalho apresentado no xvii simpósio de plantas medicinais do brasil (cuiabá-mt), Montrucchio et al. (2002) isolaram e identificaram onze substâncias em ptychopetalum olacoides, sendo elas: ácido palmítico, ácido esteárico, estigmasterol, $\beta$-sitosterol, a-amirina, glutinol, lupeol, $\beta$-sitosterol glicosilado, cafeína, adenina e teobromina. Apenas os três últimos compostos (xantinas) não haviam sido reportados na espécie.

Em estudo recente realizado por Tang, et al. (2009), novos compostos foram identificados em um extrato metanólico de cascas de ptychopetalum olacoides. Entre eles, quatro diterpenos (6a,7a-dihydroxyannonena, 7a,20-dihidroxiannonene, 7ahidroxisolidagolactona I e pticho-6a,7a-diol) foram identificados, sendo que os dois primeiros apresentaram propriedades neurotróficas. 


\subsubsection{Propriedades terapêuticas da marapuama (Ptychopetalum olacoides Benth.)}

Histórica e popularmente todas as partes têm sido usadas por suas propriedades medicinais, mas a casca e a raiz são estruturas utilizadas preferencialmente pelas atividades afrodisíacas (Costa, et al., 1991; Velasco et al., 2008). Os nativos da floresta amazônica durante muito tempo usaram a decocção das raízes e galhos da marapuama como um energético, afrodisíaco e antidiarreico (Alonso, 2007). Na medicina popular, é utilizada como tônico neuromuscular, no tratamento de ataxia, paralisia facial, neurastenia sexual, astenia circulatória e gastrointestinal (Corrêa et al., 1998; Costa et al., 1991).

Silva (1925) relata em seu artigo a eficácia da marapuama no tratamento das doenças do sistema nervoso central, também cita resultados positivos em casos de astenia gastrointestinal e circulatória, atonia da ovulação, ataxia locomotriz, nevralgias, reumatismo crônico e paralisias parciais.

Além das raízes, os ramos são também utilizados como tônico para tratamento de problemas neuromusculares. Em decocção, a planta é utilizada externamente, em banhos e massagens, para tratamento de paralisia e beribéri. Internamente, na forma de infuso, é considerada eficaz no tratamento de debilidade sexual, reumatismo, gripe e astenia cardíaca e gastrointestinal (Charam, 1987; Steinmetz, 1971). Gaebler (1979) cita também seu uso em casos de distúrbios menstruais, enquanto Toyota (1979) cita ainda seu uso em casos de poliomielite aguda, como antidisentérico e estimulante do apetite.

Apesar de ser considerada útil no tratamento de toda esta diversidade de sintomas, o objetivo principal do uso da marapuama é o tratamento das disfunções de origem sexual - como afrodisíaco e para os casos de impotência sexual (Charam, 1987; Gaebler, 1979; Júnior, 1981; Paiva, et al., 1998; Siqueira, et al., 1998; Steinmetz, 1971; Toyota, 1979; Weigel, 1907).

A Agência Nacional de Vigilância Sanitária (2019) apresenta seu emprego oficial como extrato fluido, pó e tintura de marapuama (Velasco, et al., 2008). Infusões das raízes desta planta têm sido utilizadas para o tratamento de muitas doenças em que os radicais livres são susceptíveis de serem implicados. De particular interesse são os usos entre os idosos e por pacientes em recuperação de patologias associadas com danos ao sistema nervoso central (Silva, et al., 2002).

Consistentemente com o seu uso tradicional, estudos têm demonstrado que a ingestão de Ptychopetalum olacoides facilita a recuperação da memória de pacientes que apresentaram isquemia cerebral (Silva, et al., 2004). É sugerido que a planta contém compostos capazes de melhorar a eficácia da rede celular antioxidante no cérebro, em última análise, reduzir os danos causados pelo estresse oxidativo (Siqueira, et al., 2007).

\subsection{Genciana (Gentiana lutea $\mathrm{L}$.)}

O gênero Gentiana é o maior da família das Gencianáceas, um grupo com mais de 400 espécies que se distribuem em zonas temperadas da Ásia, Europa e América (EMA (European Medicines Agency), 2010a, 2010b; Huang, et al., 2014; Mirzaee, et al., 2017; Proença da Cunha, et al., 2009); A espécie G. lutea é vulgarmente conhecida por genciana.

A espécie Gentiana lutea contém constituintes amargos localizados principalmente na raiz, sendo que os mais amargos são do tipo secoiridóide glicosídeo (2 a 8\%) (EMA (European Medicines Agency), 2010b). Gentiopicrosídeo, também conhecido como gentiamarina ou gentiopicrina, é o constituinte mais abundante, que, juntamente com a amarogentina, são os constituintes amargos mais importantes (EMA (European Medicines Agency), 2010a; Fintelmann, et al., 2010; Mirzaee, et al., 2017; Proença da Cunha, et al., 2009). Svertiamarina e amarosverina são outros exemplos de substâncias amargas isoladas desta espécie (Mirzaee, et al., 2017).

Os constituintes amargos estimulam as secreções gástricas e biliares (Fintelmann, et al., 2010; Olivier \& van Wyk, 2013; Proença da Cunha, et al., 2009). Existem dois mecanismos propostos para a ação de moléculas amargas na função digestiva: (1) As moléculas amargas estimulam a ação do nervo vago (parte do sistema parassimpático) nas glândulas salivares e estômago. (2) As moléculas amargas atuam diretamente sobre mucosa da parte superior do sistema gastrointestinal, especialmente nos recetores de substâncias amargas, aumentando a produção de saliva e sucos gástricos. Esta teoria é apoiada por estudos recentes 
que mostram que existem recetores de moléculas amargas e doces no estômago, duodeno, ileum e cólon de ratinhos (EMA (European Medicines Agency), 2010a; Mirzaee, et al., 2017).

Gentiana lutea é uma planta herbácea perene, atingindo 1-2 m (3,3-6,6 pés) de altura, com folhas lanceoladas largas a elípticas de 10-30 cm (3,9-11,8 in) de comprimento e 4-12 cm (1,6-4,7 in) de largura. As flores são amarelas, com a corola distribuída quase até a base em 5-7 pétalas estreitas (Prakash, et al., 2017).

Prakash et al. (2017) afirmaram que a planta é relatada como antioxidante, antifúngica, antiinflamatória estomacal, aperitivo e propriedades imunomodulatórias, etc. Gentiana lutea é uma importante fonte de amargo fitoconstituintes. Tradicionalmente, a planta é usada como tônico estomacal, tônico amargo, tônico digestivo, na dispepsia, ineficiência gástrica em bebês, diarreia catarral, anemia, malária etc.

\subsubsection{Composição fitoquímica da genciana (Gentiana lutea $\mathrm{L}$.)}

A raiz seca de genciana contém gentiseína, gentisina, iso-gentisina, gentinina, gentiamarina e glicosídeos amargos, junto com genciana ácido (gentisina), sendo o último fisiologicamente inativo (Atkinson, et al., 1969).

Os principais constituintes de Gentiana lutea são iridóides amargos comumente conhecidos como ácido logânico, secoiridoides (Wu, et al., 2016), xantonas, gentiopicrina, swertiamarin, amarogentina e amaroswerin, que é o mais amargo de todos os compostos nesta substância (Aberham, et al., 2011; Hostettmann, et al., 1973; Verotta, 1985).

O glicosídeo secoiridoide contém gentiopicrosídeo (também conhecido como gentiopicrina e gentiamarina) (Ando, et al., 2007). Gentiopicrin são glicosídeos cristalinos amarelo pálido amargo que ocorrem na raiz fresca e podem ser isolados dela tratando com álcool fervente. Gentinina cristalina glicosídeo não é uma substância química pura, mas uma mistura de gentiopicrina e uma substância corante gentisina (genciana) ou ácido gentlânico. Outros constituintes incluem dois glicosídeos xantonas em que a porção aglicona é conhecida como gentiosídeos (até 0,1\%), tal como gentisina (genciana) e isogentisina (Aberham, et al., 2007; Menković, et al., 2016).

Quantidade de rastreamento de um alcalóides, fitoesteróis, triterpenos e óleo essencial também são relatados em raízes de genciana amarela (Citová, et al., 2008; Leung, 1980). Contendo até 1\% de xantonas: gentisina ou gentianina, isogentisina, metilgentisina, 1-hidroxi-3, 7-dimetoxixantona, 1,3,7-trimetoxixantona, dihidroxi-1,3- dimetoxi-2,7-xantona e gentisina-1- Oprimverosídeo e gentiosídeo-7-O-primverosídeo. Xantonas também são responsáveis pelo cor amarela da raiz (Hayashi \& Yamagishi, 1988; Hostettmann, et al., 1973; Pan, et al., 2016).

Gentiana lutea contém amargo trissacarídeos, gentianose, que na hidrólise produz duas moléculas de glicose e uma molécula de frutose. Os carboidratos da Gentiana lutea são dextrose, laevulose, sacarose e gentianose, um açúcar cristalino fermentável (Rossetti, et al., 1984). A raiz e o rizoma também contêm pequenas quantidades de aminoácidos livres. A planta Gentiana lutea também contém pectina, tanino, triterpinas (conhecidas como $\beta$-amirina, lupeol) e vestígios de óleos essenciais $(0,1-0,2 \%)$ responsáveis pela característica sabor. É isento de amido e rende de 3 a 4\% de cinzas (Shah, 2009).

\subsubsection{Propriedades terapêuticas da genciana (Gentiana lutea L.)}

Gentiana lutea L. é amplamente utilizada como remédio popular para a mitigação, prevenção e tratamento de várias doenças. A erva tradicional de genciana tem sido usada na fitoterapia da Europa e do Oriente ao longo de 3.000 anos, sendo amplamente utilizada como um tônico amargo, colagogos, emmenagogo, febrífugo, refrigerante, gastroprotetor, estimulante de apetite, antiácido e acelerador do metabolismo (Lloyd Brothers, 1907).

Os extratos são aplicados em uma variedade de alimentos, cosméticos e alguns produtos antifumo. A planta foi usada externamente como cicatrizantes e internamente como analgésico e para tratar inflamação artrítica e icterícia (Finley Ellingwood, 1919). 
Gentiana lutea apresenta propriedades digestivas devido à presença de amarogentina. Algumas variedades de genciana estimulam os receptores gustativos no língua, causando um aumento na produção de saliva e gástrica secreção. A erva também é usada como estimulante da vesícula biliar e do fígado, encorajando-os a funcionar com mais eficiência. A planta também é um remédio para diarreia, com relaxamento das mucosas, possuindo propriedades antimalárica e sendo efíciente contra indigestão e sintomas de depressão (Khare, 2011).

Tanto na fitoterapia ocidental como na oriental, a raiz da Gentiana lutea é utilizado com finalidades terapêuticas. Os constituintes amargos estimulam as secreções gástricas e biliares, sendo que o uso de tônicos amargos na falta de apetite e má digestão é uma prática ancestral. Conforme descrito anteriormente, esta planta tem uma ação tônica do estômago, atuando diretamente sobre a mucosa gástrica, estimulando a libertação de gastrina e dos sucos gástricos. Além disso, aumenta a produção de saliva e bílis (colerético) e, por isso, promove a função digestiva. Por não conter taninos, a Gentiana lutea não tem efeitos adstringentes e irritantes do estômago (EMA(European Medicines Agency), 2010a; Fintelmann, et al., 2010; Olivier \& van Wyk, 2013; Proença da Cunha, et al., 2009).

De acordo com monografia realizada pelo Comitê para os Medicamentos à Base de Plantas da Agência Europeia do Medicamento, a Gentiana lutea tem utilização tradicional aprovada quando utilizada isoladamente ou em combinação com outras plantas amargas e/ou aromáticas para o tratamento de dispepsia/alterações gastrointestinais, alterações coleréticas e perda de apetite (EMA (European Medicines Agency), 2010a).

\subsection{Quassia (Quassia amara L.)}

A Quassia amara L. é uma angiosperma pertencente à família das Simaroubaceae. Esta família é composta por 25 gêneros e 200 espécies, com centro de diversidade na região neotropical (Ribeiro, 1999).

Barroso (1991) revela que o nome Quassia foi dado em homenagem a um negro do Suriname, de nome Quassi, que em meados do século XVIII adquiriu fama por curar doentes de febres malignas com o auxílio desta planta. Para o referido autor, no Brasil o gênero é predominante na região Norte, distribuindo-se geograficamente até o Maranhão.

A Quassia amara L. é conhecida popularmente como pau-amargo, murubá, marupá, quina-de-caiena, quássia, simaruba e quina, fornece madeira que pode ser utilizada nas obras de caixotaria e carpintaria (Berg, 1982; Corrêa, 1984; Le Cointe, 1947). Cascas do tronco são tradicionalmente utilizadas como antimicrobiana, antianêmica, antimalárica e no tratamento de distúrbios gastrintestinais. Suas folhas são usadas na forma de chá e alcoolato como febrífugo, tônico, digestivo, no tratamento dos males do estômago e da vesícula (Macedo, et al., 2005).

Quassia amara contém quassin, o substância mais amarga encontrada na natureza. Todas as partes de Quassia são úteis, incluindo raiz, casca, caule, madeira do coração, folha e flor (Remya \& Goyal, 2017).

A quássia é uma arvoreta de $4-7 \mathrm{~m}$ de altura, com folhas compostas, com cinco folíolos, imparipinadas, ráquis e pecíolos alados, folíolos oblanceolados, ápice abruptamente acuminado e base atenuada (Macedo et al., 2005).

A planta é rica em diversos compostos como os quassinóides e os alcalóides betacarbolina e cantin-6, com atividade antiplasmódio, fago-repelente e antifertilidade (Ajaiyeoba, et al., 1999). O chá da casca de Q. amara é utilizado para o tratamento da dor, talvez um —narcótico (Duke \& Vásquez, 1994). De fato, foi sugerido que a espécie possa conter componentes analgésicos (Toma, et al., 2003).

No Brasil, as propriedades terapêuticas atribuídas à quina se baseiam apenas na cultura popular, fundamentada em experiências de sua utilização pelas populações que a cultivam em quintais ou que habitam áreas onde ela ocorre naturalmente. Duke \& Vásquez (1994) revelam que estão sendo feitos estudos clínicos no Texas, Guatemala, República Dominicana, México e Panamá, para que a quassina seja usada também no tratamento de carcinomas e células infectadas com o vírus HIV. 


\subsubsection{Composição fitoquímica da quassia lenho (Quassia amara L.)}

Muitos compostos das folhas, caule e seiva de Quassia amara L. já foram isolados, como os alcalóides $\beta$ carbolina (1-vinil-4,8-dimetoxi- $\beta$-carbolina, 1-metoxicarbonil- $\beta$-carbolina e Nmetoxi-1-vinil- $\beta$-carbolina), alcalóides indólicos (3-metilcantin-2,6-diona, 5-hidroxi-3-metil4-metoxicantin-2,6-diona, 3-metilcantin-5,6-diona, 2-metoxicantin-6-ona, 3-N-óxido de 5-hidroxi-4-metoxicantin-6-ona e 5-hidroxi-4-metoxicantin-6-ona), esteróides ( $\beta$-sitosterol, stigmasterol e campesterol) e os quassinóides (quassina, neoquassina, simalicalactona D e E, picrassins B, H, I e J). Este último grupo é, geralmente, descrito como o grupo mais característico desta planta (Barbetti, et al., 1987, Barbetti, et al., 1993; Barbetti et al., 1990; Njar, et al., 1993).

\subsubsection{Propriedades terapêuticas da quassia lenho (Quassia amara L.)}

A Quassia amara L. é utilizada na medicina popular como antimicrobiana, antimalárica, anti-inflamatória, no combate à anemia e no tratamento de problemas do trato gastrointestinal; o uso como repelente e inseticida também é comum (Berg, 1982; Corrêa, 1984; Macedo, et al., 2005; Ribeiro, 1999).

A "quassina" é um dos princípios ativos produzidos pela quina. Trata-se de um alcalóide de forte sabor amargo, ao qual se atribui propriedades inseticidas e medicinais. É utilizado no controle de pragas (Lameira \& Pinto, 1995; Le Cointe, 1947) Na medicina popular, vem sendo utilizado há muitos anos, sob a forma de chás e alcoolatos, no combate a verminoses, anemia, males do estômago e intestino, e como anti-inflamatório e antimalárico (Berg, 1982; Corrêa, 1984). Albuquerque, (1989) cita que o chá das folhas ou casca é febrífugo, adstringente e serve para atonia do aparelho digestivo.

De acordo com (Rocha Neto, et al., 1997), as pesquisas sobre o aproveitamento da quassina no combate a doenças tropicais, como a malária, vêm sendo intensificadas por pesquisadores do Hospital Universitário Barros Barreto e do Instituto Evandro Chagas, Belém-PA.

\section{Considerações Finais}

A investigação promovida ao longo das últimas décadas acerca das propriedades - especialmente em termos fitoterápicos - das quatro espécies revisadas corrobora o conhecimento adquirido e propagado pelas comunidades das regiões em que essas espécies vegetais são nativas no que concerne sua utilidade e benefícios na solução de diversos males.

Portanto, conclui-se que existe grande potencial para o aprofundamento de pesquisas nas espécies vegetais revisadas, principalmente no que se refere ao seu uso fitoterápico - uma vez que essas tem mostrado auxiliar nos mais diversos quadros de saúde. Além disso, a condução de mais estudos se torna também necessária para a promoção da eficácia terapêutica das espécies em seres humanos, sobretudo com um enfoque em ensaios não clínicos e clínicos.

\section{Referências}

Aberham, A., Pieri, V., Croom, E. M., Ellmerer, E., \& Stuppner, H. (2011). Analysis of iridoids, secoiridoids and xanthones in Centaurium erythraea, Frasera caroliniensis and Gentiana lutea using LC-MS and RP-HPLC. Journal of Pharmaceutical and Biomedical Analysis, 54(3), 517-525. 10.1016/j.jpba.2010.09.030

Aberham, A., Schwaiger, S., Stuppner, H., \& Ganzera, M. (2007). Quantitative analysis of iridoids, secoiridoids, xanthones and xanthone glycosides in Gentiana lutea L. roots by RP-HPLC and LC-MS. Journal of Pharmaceutical and Biomedical Analysis, 45(3), 437-442. 10.1016/j.jpba.2007.07.001

Aftab, T., \& Hakeem, K. R. (Orgs.). (2021). Bioactive secondary metabolites of medicinal and aromatic plants and their disease-fighting properties. In Medicinal and Aromatic Plants: Healthcare and Industrial Applications. New York, United States: Springer International Publishing. 10.1007/978-3-030-58975-2

Agência Nacional de Vigilância Sanitária. (2019). Farmacopéia brasileira (6a ed.), 1-1. Agência Nacional de Vigilância Sanitária. https://www.gov.br/anvisa/ptbr/assuntos/farmacopeia/farmacopeia-brasileira/arquivos/7985json-file-1

Ajaiyeoba, E., Abalogu, U., Krebs, H., \& Oduola, A. (1999). In vivo antimalarial activities of Quassia amara and Quassia undulata plant extracts in mice. Journal of Ethnopharmacology, 67(3), 321-325. 10.1016/S0378-8741(99)00073-2

Albuquerque, J. de. (1989). Plantas medicinais de uso popular. ABEAS/MEC.

Alonso, J. (2007). Tratado de fitofármacos y nutracéuticos. Corpus. 
Andersen, T., \& Fogh, J. (2001). Weight loss and delayed gastric emptying following a South American herbal preparation in overweight patients. Journal of Human Nutrition and Dietetics, 14(3), 243-250. 10.1046/j.1365-277X.2001.00290.x

Ando, H., Hirai, Y., Fujii, M., Hori, Y., Fukumura, M., Niiho, Y., Nakajima, Y., Shibata, T., Toriizuka, K., \& Ida, Y. (2007). The chemical constituents of fresh Gentian Root. Journal of Natural Medicines, 61(3), 269-279. 10.1007/s11418-007-0143-x

Araújo, J. A., Araújo, J. A., Araújo, T. P., Anjos, D. F., \& Vieira, J. S. C. (2010). Avaliação físico-química do guaraná (Paullinia cupana) em pó utilizado na produção de bebidas estimulantes comercializadas em Zé Doca - MA. Anais do Congresso Norte Nordeste de Pesquisa e Inovação. Congresso Norte Nordeste de Pesquisa e Inovação, Maceió, AL.

Atkinson, J. E., Gupta, P., \& Lewis, J. R. (1969). Some phenolic constituents of Gentiana lutea. Tetrahedron, 25(7), 1507-1511. 10.1016/S0040-4020(01)82723$\mathrm{X}$

Atroch, A. L. (2009). Avaliação de progênies de meios irmãos de guaranazeiro (Paullinia cupana var. Sobilis (Mart.) Ducke) utilizando caracteres morfoagronômicos [Tese de Doutorado]. Universidade Federal do Amazonas.

Audi, E., \& Mello, J. (2000). Efeito antidepressivo do extrato da droga vegetal guaraná (Paullinia cupana var. Sorbilis (Martius) Ducke). Fundação Universidade Estadual de Maringá, BR Patent\# PI00066389, Cl. Int. A61P, 25(24), A61K.

Barbetti, P., Grandolini, G., Fardella, G., \& Chiappini, I. (1987). Indole alkaloids from Quassia amara. Planta medica, 53(03), 289-290. 10.1055/s-2006-962709

Barbetti, P., Grandolini, G., Fardella, G., \& Chiappini, I. (1993). Quassinoids from Quassia amara. Phytochemistry, 32(4), 1007-1013. 10.1016/00319422(93)85245-M

Barbetti, P., Grandolini, G., Fardella, G., Chiappini, I., \& Mastalia, A. (1990). New canthin-6-one alkaloids from Quassia amara. Planta medica, 56(02), 216217. 10.1055/s-2006-960928

Barroso, G. M. (1991). Sistemática de angiospennas do Brasil. (Vol. 2). FV/Imprensa Universitária.

Basile, A., Ferrara, L., Pezzo, M. D., Mele, G., Sorbo, S., Bassi, P., \& Montesano, D. (2005). Antibacterial and antioxidant activities of ethanol extract from Paullinia cupana Mart. Journal of Ethnopharmacology, 102(1), 32-36. 10.1016/j.jep.2005.05.038

Basso, L. A., Silva, L. H. P. da, Fett-Neto, A. G., Azevedo Junior, W. F. de, Moreira, Í. de S., Palma, M. S., Calixto, J. B., Astolfi Filho, S., Santos, R. R. dos, Soares, M. B. P., \& Santos, D. S. (2005). The use of biodiversity as source of new chemical entities against defined molecular targets for treatment of malaria, tuberculosis, and T-cell mediated diseases: A review. Memórias do Instituto Oswaldo Cruz, 100(6), 475-506. 10.1590/S0074-02762005000600001

Berg, M. E. (1982). Plantas medicinais na Amazônia: Contribuição ao seu conhecimento sistemático. CNPq/Programa Trópico Úmido.

Bhattacharjee, I., Chatterjee, S. K., Chatterjee, S., \& Chandra, G. (2006). Antibacterial potentiality of Argemone mexicana solvent extracts against some pathogenic bacteria. Memórias do Instituto Oswaldo Cruz, 101(6), 645-648. 10.1590/S0074-02762006000600011

Bittencourt, L. da S., Zeidán-Chuliá, F., Yatsu, F. K. J., Schnorr, C. E., Moresco, K. S., Kolling, E. A., Gelain, D. P., Bassani, V. L., \& Moreira, J. C. F. (2014). Guarana (Paullinia cupana Mart.) prevents $\beta$-amyloid aggregation, generation of advanced glycation-end products (AGEs), and acrolein-induced cytotoxicity on human neuronal-like cells. Phytotherapy Research, 28(11), 1615-1624. 10.1002/ptr.5173

Bydlowski, S., Yunker, R., \& Subbiah, M. (1988). A novel property of an aqueous guaraná extract (Paullinia cupana): Inhibition of platelet aggregation in vitro and in vivo. Brazilian Journal of Medical and Biological Research, 21(3), 535-538.

Campos, A. R., Barros, A. I. S., Santos, F. A., \& Rao, V. S. N. (2003). Guarana (Paullinia cupana Mart.) offers protection against gastric lesions induced by ethanol and indomethacin in rats. Phytotherapy Research, 17(10), 1199-1202. 10.1002/ptr.1212

Charam, I. (1987). Há açöes afrodisiácas nas plantas medicinais do Brasil? Folha méd, 303-309. https://pesquisa.bvsalud.org/portal/resource/pt/lil-42338

Citová, I., Ganzera, M., Stuppner, H., \& Solich, P. (2008). Determination of gentisin, isogentisin, and amarogentin in Gentiana lutea L. by capillary electrophoresis. Journal of Separation Science, 31(1), 195-200. 10.1002/jssc.200700325

Corrêa, A. D., Batista, R. S., \& Quintas, L. E. M. (1998). Plantas medicinais: Do cultivo à terapêutica. Vozes. https://books.google.com.br/books?id=wQmYMwEACAAJ

Corrêa, M. P. (1984). Dicionário das plantas úteis do Brasil e das exóticas cultivadas. (Vol. 2). Rio de Janeiro, Brasil: Imprensa Nacional.

Costa Krewer, C., Ribeiro, E. E., Ribeiro, E. A. M., Moresco, R. N., Ugalde Marques da Rocha, M. I., Santos Montagner, G. F. F., Machado, M. M., Viegas, K., Brito, E., \& Cruz, I. B. M. (2011). Habitual intake of guaraná and metabolic morbidities: An epidemiological study of an elderly amazonian population. Phytotherapy Research, 1367-1374. 10.1002/ptr.3437

Costa, P. R. C., Santos, S. M. B. P., Silva, L. E. W., \& Menezes, C. S. (1991). Plantas medicinais climatizadas da região amazônica. Governo do Estado do Amazonas.

da Silva, A. L., Bardini, S., Nunes, D. S., \& Elisabetsky, E. (2002). Anxiogenic properties of Ptychopetalum olacoides Benth. (Marapuama). Phytotherapy Research, 16(3), 223-226. 10.1002/ptr.825

da Silva, A. L., Piato, Â. L. S., Bardini, S., Netto, C. A., Nunes, D. S., \& Elisabetsky, E. (2004). Memory retrieval improvement by Ptychopetalum olacoides in young and aging mice. Journal of Ethnopharmacology, 95(2-3), 199-203. 10.1016/j.jep.2004.07.019

da Silva, W. G., Rovellini, P., Fusari, P., \& Venturini, S. (2015). Guaraná-Paullinia cupana, (HBK): Estudo da oxidação das formas em pó e em bastões defumados. Revista de Ciências Agroveterinárias, 14(2), 117-123. Obtido de: https://www.revistas.udesc.br/index.php/agroveterinaria/article/view/5637 
Dalonso, N., \& de Oliveira Petkowicz, C. L. (2012). Guarana powder polysaccharides: Characterisation and evaluation of the antioxidant activity of a pectic fraction. Food Chemistry, 134(4), 1804-1812. 10.1016/j.foodchem.2012.03.088

Derkach, T., \& Tarasenko, H. (2021). Chemistry of medicinal plants as an integral part of ecological education. E3S Web of Conferences, $280,11015$. $10.1051 / \mathrm{e} 3$ sconf $/ 202128011015$

Duarte, M. C. T. (2006). Atividade antimicrobiana de plantas medicinais e aromáticas utilizadas no Brasil. Revista MultiCiência, 7(1), 1-16. www.ccs.ufpb.br/nephf/contents/documentos/artigos/fitoterapia/atividade-antimicrobiana-de-

plantas/@@download/file/Atividade\%20Antimicrobiana\%20de\%20Plantas.pdf

Duke, J. A., \& Vásquez, V. M. (1994). Amazonian ethnobotanical dictionary: English version. Boca Raton, USA: CRC Press. https://books.google.com.br/books?id=jswluAAACAAJ

EMA (European Medicines Agency). (2010a). Assessment report on Gentiana lutea l., radix (EMA/HMPC/578322/2008). European Medicines Agency.

EMA (European Medicines Agency). (2010b). Community herbal monograph on Gentiana lutea l., radix (EMA/HMPC/578324/2008). European Medicines Agency.

EMBRAPA. (2005). Cultura do guaranazeiro no Amazonas $\left(4^{\circ}\right.$ ed). Manaus, Brasil: EMBRAPA da Amazônia Oriental. https://www.infoteca.cnptia.embrapa.br/bitstream/doc/678408/1/SistemaProdGuarana.pdf

Espinola, E. B., Dias, R. F., Mattei, R., \& Carlini, E. A. (1997). Pharmacological activity of Guarana (Paullinia cupana Mart.) in laboratory animals. Journal of Ethnopharmacology, 55(3), 223-229. 10.1016/S0378-8741(96)01506-1

Finley Ellingwood, M. (1919). American materia medica, therapeutics and pharmacognosy. Chicago, USA: Ellingwood's Therapeutist. O. http://swsbm.henriettesherbal.com/Ellingwoods/Ellingwoods_plants_only.pdf

Fintelmann, V., Weiss, R. F., \& Fintelmann, V. (2010). Manual de fitoterapia (11 ed). São Paulo, Brasil: Guanabara Koogan.

Firmo, W. da C. A., de Menezes, V. de J. M., de Castro Passos, C. E., Dias, C. N., Alves, L. P. L., Dias, I. C. L., Neto, M. S., \& Olea, R. S. G. (2011). Contexto histórico, uso popular e concepção científica sobre plantas medicinais. Cadernos de pesquisa, 18(Especial), 90-95. http://www.periodicoseletronicos.ufma.br/index.php/cadernosdepesquisa/article/view/746

Forgacs, P. (1983). Etudes phytochimiques et activités biologiques de 18 plantes de la Guyane Françäíse. Plantes Médicinales et Phytothérapie, 17(1), 22-32. https://core.ac.uk/download/pdf/39873902.pdf

Fukumasu, H., Avanzo, J. L., Nagamine, M. K., Barbuto, J. A., Rao, K. V., \& Dagli, M. L. Z. (2008). Paullinia cupana Mart var. Sorbilis, guaraná, reduces cell proliferation and increases apoptosis of B16/F10 melanoma lung metastases in mice. Brazilian Journal of Medical and Biological Research, 41(4), 305-310. $10.1590 / \mathrm{S} 0100-879 \mathrm{X} 2008000400008$

Gaebler, H. (1970). Revival of the drug Muira puama. Deut. Apoth, 22(3), 94-96.

Griebel, C. (1912). Detection of muira-puama extract. Z. Nahr. Genussm, 24, 687.

Harland, B. F. (2000). Caffeine and nutrition. Nutrition (Burbank, Los Angeles County, Calif.), 16(7-8), 522-526. 10.1016/s0899-9007(00)00369-5

Harrold, J. A., Hughes, G. M., O'Shiel, K., Quinn, E., Boyland, E. J., Williams, N. J., \& Halford, J. C. G. (2013). Acute effects of a herb extract formulation and inulin fibre on appetite, energy intake and food choice. Appetite, 62, 84-90. 10.1016/j.appet.2012.11.018

Haskell, C. F., Kennedy, D. O., Wesnes, K. A., Milne, A., \& Scholey, A. (2007). A double-blind, placebo-controlled, multi-dose evaluation of the acute behavioural effects of guaraná in humans. Journal of psychopharmacology, 21(1), 65-70. 10.1177\%2F0269881106063815

Hayashi, T., \& Yamagishi, T. (1988). Two xanthone glycosides from Gentiana lutea. Phytochemistry, 27(11), 3696-3699. 10.1016/0031-9422(88)80805-7

Heckman, M. A., Weil, J., \& de Mejia, E. G. (2010). Caffeine (1, 3, 7-trimethylxanthine) in foods: A comprehensive review on consumption, functionality, safety, and regulatory matters. Journal of Food Science, 75(3), R77-R87. 10.1111/j.1750-3841.2010.01561.x

Henman, A. R. (1982). Guaraná (Paullinia cupana var. sorbilis): Ecological and social perspectives on an economic plant of the central amazon basin. Journal of Ethnopharmacology, 6(3), 311-338. 10.1016/0378-8741(82)90054-X

Hertz, E., Cadoná, F. C., Machado, A. K., Azzolin, V., Holmrich, S., Assmann, C., Ledur, P., Ribeiro, E. E., De Souza Filho, O. C., Mânica-Cattani, M. F., \& Da Cruz, I. B. M. (2015). Effect of Paullinia cupana on MCF-7 breast cancer cell response to chemotherapeutic drugs. Molecular and Clinical Oncology, 3(1), 3743. $10.3892 / \mathrm{mco} .2014 .438$

Hostettmann, K., Bellmann, G., Tabacchi, R., \& Jacot-Guillarmond, A. (1973). Phytochemistry of the Gentiana genus III. Flavonic and xanthonic compounds in the leaves of Gentiana lutea. Helv Chim Acta, 56(8), 3050-3054.

Huang, S.-H., Agrawal, D. C., Wu, F.-S., \& Tsay, H.-S. (2014). In vitro propagation of Gentiana scabra Bunge - an important medicinal plant in the chinese system of medicines. Botanical Studies, 55(1), 56. 10.1186/s40529-014-0056-4

IBGE (Instituto Brasileiro de Geografia e Estatística). (2016). Levantamento sistemático da produção agrícola (in Portuguese). In: CONAGRO (Ed) (p. 1-113). https://www.ibge.gov.br/estatisticas/economicas/agricultura-e-pecuaria/9201-levantamento-sistematico-da-producao-agricola.html? $=\& \mathrm{t}=0$-que-e

Júnior, S. (1981). Plantas eróticas. Rio de Janeiro, Brasil: Codecri. https://books.google.com.br/books?id=n_1GAAAAYAAJ 
Kaur, N., \& Ahmed, T. (2021). Bioactive secondary metabolites of medicinal and aromatic plants and their disease-fighting properties. In Medicinal and Aromatic Plants: Healthcare and Industrial Applications (p. 783). Basingstoke, United Kingdom: Springer Nature. https://books.google.com.br/books?hl=ptBR\&lr $=\& i d=$ LRomEAAAQBAJ\&oi $=$ fnd $\& p g=$ PA113\&dq=Bioactive+Secondary + Metabolites + of + Medicinal + and + Aromatic + Plants + and + Their + DiseaseFighting+Properties\&ots $=\mathrm{q}-\mathrm{RcU}$ yefo8\&sig=e09mRQidEiBAz0-

3ZRReR_MxuHA\#v=onepage\&q=Bioactive $\% 20$ Secondary $\% 20$ Metabolites $\% 20$ of $\% 20$ Medicinal $\% 20$ and $\% 20$ Aromatic\%20Plants $\% 20$ and $\% 20$ Their $\% 20$ Disea se-Fighting $\% 20$ Properties $\& \mathrm{f}=$ false

Khan, H. (2014). Medicinal plants in light of history: Recognized therapeutic modality. Journal of Evidence-Based Complementary \& Alternative Medicine, 19(3), 216-219. 10.1177/2156587214533346

Khare, C. P. (2011). Indian herbal remedies: Rational Western therapy, ayurvedic, and other traditional usage, Botany. Berlin, Germany: Springer science \& business media.

Kuskoski, E. M., Fett, R., García Asuero, A., \& Troncoso González, A. M. (2005). Propiedades químicas y farmacológicas del fruto guaraná (Paullinia cupana). Vitae, 12(2), 45-52. http://www.scielo.org.co/pdf/vitae/v12n2/v12n2a06.pdf?

Lameira, O. A., \& Pinto, J. E. B. P. (1995). Indução de calós em quina (Quassia amara L.) e erva baleeira. Anais do $5^{\circ}$ Congresso Brasileiro de Biologia Vegetal. Congresso Brasileiro de Biologia Vegetal, Lavras, MG.

Le Cointe, P. (1947). Amazônia Brasileira: Árvores e plantas úteis (indigenas e aclimatadas). (2a ed). Editora Nacional.

Leung, A. Y. (1980). Encyclopedia of common natural ingredients used in food, drugs, and cosmetics.

Lima, N. da S., Caria, C. R. e P., Gambero, A., \& Ribeiro, M. L. (2019). The effect of guarana (Paullinia cupana) on metabolic and inflammatory parameters in adult male mice programmed by maternal obesity. European Journal of Nutrition, 58(2), 765-774. 10.1007/s00394-018-1686-1

Lima, N. H. Q., Oliveira, L. V., Coelho, A. L., \& Dantas, C. (2018). Estudo teórico da atividade antioxidante de compostos fenólicos do buriti (Mauritia flexuosa L. f.) oor diferentes mecanismos vista por DFT. 58 Congresso Brasileiro de Química. Obtido em: http://www.abq.org.br/cbq/2018/trabalhos/3/1738-26800.html

Lima, N., Numata, E., Mesquita, L., Dias, P., Vilegas, W., Gambero, A., \& Ribeiro, M. (2017). Modulatory effects of guarana (Paullinia cupana) on adipogenesis. Nutrients, 9(6), 635. 10.3390/nu9060635

Lima, P. G. C., Coelho-Ferreira, M., \& da Silva Santos, R. (2016). Perspectives on medicinal plants in public markets across the Amazon: A review. Economic Botany, 70(1), 64-78. 10.1007/s12231-016-9338-y

Lima, W., Carnevalijr, L., Eder, R., Costarosa, L., Bacchi, E., \& Seelaender, M. (2005). Lipid metabolism in trained rats: Effect of guarana (Mart.) supplementation. Clinical Nutrition, 24(6), 1019-1028. 10.1016/j.clnu.2005.08.004

Lloyd Brothers. (1907). Dose book of Specific Medicines. Lloyd Brothers.

Macedo, E. G., Potiguara, R. de V., \& Rocha Neto, O. da. (2005). Anatomia foliar de Quassia amara L. (Simaroubaceae), uma espécies medicinal e inseticida. Embrapa Amazônia Oriental-Artigo em periódico indexado (ALICE). Obtido em: http://www.alice.cnptia.embrapa.br/alice/handle/doc/577889

Machado, K. N., Freitas, A. A. de, Cunha, L. H., Faraco, A. A. G., Pádua, R. M. de, Braga, F. C., Vianna-Soares, C. D., \& Castilho, R. O. (2018). A rapid simultaneous determination of methylxanthines and proanthocyanidins in Brazilian guaraná (Paullinia cupana Kunth.). Food Chemistry, 239, 180-188. 10.1016/j.foodchem.2017.06.089

Majhenič, L., Škerget, M., \& Knez, Ž. (2007). Antioxidant and antimicrobial activity of guarana seed extracts. Food Chemistry, 104(3), 1258-1268. 10.1016/j.foodchem.2007.01.074

Marques, L. L. M., Panizzon, G. P., Aguiar, B. A. A., Simionato, A. S., Cardozo-Filho, L., Andrade, G., de Oliveira, A. G., Guedes, T. A., \& Mello, J. C. P. de. (2016). Guaraná (Paullinia cupana) seeds: Selective supercritical extraction of phenolic compounds. Food Chemistry, 212, 703-711. 10.1016/j.foodchem.2016.06.028

Martins, C. A. (2010). Avaliação da atividade antioxidante in vitro e in vivo do guaraná (Paullinia cupana) em pó [Dissertação de Mestrado]. Universidade de São Paulo.

Mehr, C. B., Biswal, R. N., Collins, J. L., \& Cochran, H. D. (1996). Supercritical carbon dioxide extraction of caffeine from Guarana. The Journal of Supercritical Fluids, 9(3), 185-191. 10.1016/S0896-8446(96)90031-5

Menković, N., Živković, J., Šavikin, K., Janković, T., Zdunić, G., \& Pljevljakušić, D. (2016). Optimization of ultrasound-assisted extraction of isogentisin from Gentiana lutea L. roots by response surface methodology. Planta Medica, 81(S 01), S1-S381. 10.1055/s-0036-1597014

Mirzaee, F., Hosseini, A., Jouybari, H. B., Davoodi, A., \& Azadbakht, M. (2017). Medicinal, biological and phytochemical properties of Gentiana species. Journal of Traditional and Complementary Medicine, 7(4), 400-408. 10.1016/j.jtcme.2016.12.013

Montrucchio, D. P. (2001). Estudo Fitoquímico e de Atividade Antimicrobiana de Ptychopetalum olacoides Bentham [Dissertação de Mestrado]. Universidade Federal do Paraná.

Montrucchio, D. P., Miguel, O. G., \& Miguel, M. D. (2002). Ptychopetalum olacoides Bentham: Principais características botânicas, fitoquímicas e farmacológicas. Rev. ciênc. farm, 11-24.

Njar, V. C., Alao, T. O., Okogun, J. I., \& Holland, H. L. (1993). 2-Methoxycanthin-6-one: A new alkaloid from the stem wood of Quassia amara. Planta medica, 59(03), 259-261. 10.1055/s-2006-959664

Ogawa, N., \& Ueki, H. (2007). Clinical importance of caffeine dependence and abuse. Psychiatry and Clinical Neurosciences, 61(3), 263-268. 10.1111/j.14401819.2007.01652.x 
Olivier, D. K., \& van Wyk, B.-E. (2013). Bitterness values for traditional tonic plants of southern Africa. Journal of Ethnopharmacology, 147(3), 676-679. 10.1016/j.jep.2013.03.059

Otobone, F. J., Sanches, A. C., Nagae, R. L., Martins, J. V. C., Obici, S., Mello, J. C. P. de, \& Audi, E. A. (2005). Effect of crude extract and its semi purified constituents from guaraná seeds [Paullinia cupana var. Sorbilis (Mart.) lucke] on cognitive performance in Morris water maze in rats. Brazilian Archives of Biology and Technology, 48, 723-728. 10.1590/S1516-89132005000600007

Paiva, L., Rao, V., \& Silveira, E. (1998). Effects of Ptychopetalum olacoides extract on mouse behaviour in forced swimming and open field tests. Phytotherapy Research: An International Journal Devoted to Pharmacological and Toxicological Evaluation of Natural Product Derivatives, 12(4), 294-296. 10.1002/(SICI)1099-1573(199806)12:4\%3C294::AID-PTR230\%3E3.0.CO;2-3

Pan, Y., Zhao, Y.-L., Zhang, J., Li, W.-Y., \& Wang, Y.-Z. (2016). Phytochemistry and pharmacological activities of the genus Gentiana (Gentianaceae). Chemistry \& biodiversity, 13(2), 107-150. 10.1002/cbdv.201500333

Pankow, E., \& Auterhoff, H. (1969). Inhaltsstoffe von Muira puama. 2. Mitteilung. Archiv der Pharmazie, 302(3), 209-212. 10.1002/ardp.19693020309

Portella, R. de L., Barcelos, R. P., da Rosa, E. J. F., Ribeiro, E. E., da Cruz, I. B. M., Suleiman, L., \& Soares, F. A. A. (2013). Guaraná (Paullinia cupana Kunth) effects on LDL oxidation in elderly people: An in vitro and in vivo study. Lipids in Health and Disease, 12(1), 12. 10.1186/1476-511X-12-12

Prakash, O., Singh, R., Kumar, S., Srivastava, S., \& Ved, A. (2017). Gentiana lutea Linn.(Yellow Gentian): A comprehensive. Journal of Ayurvedic and Herbal Medicine, 3(3), 175-181. Obtido em ahttps://www.innerpath.com.au/matmed/research/Gentiana\%5Elutea.pdf http://www.innerpath.com.au/matmed/r esearch/Gentiana\%5Elutea.pdf

Proença da Cunha, A., Pereira da Silva, A., \& Roque, O. R. (2009). Plantas e produtos vegetais em fitoterapia (3a ed). Fundação Calouste Gulbenkian.

Rangel, M. P., Mello, J. C. P. de, \& Audi, E. A. (2013). Evaluation of neurotransmitters involved in the anxiolytic and panicolytic effect of the aqueous fraction of Paullinia cupana (guaraná) in elevated T maze. Revista Brasileira de Farmacognosia, 23, 358-365. 10.1590/S0102-695X2013005000024

Remya, E., \& Goyal, M. (2017). Therapeutic evaluation of Quassia amara Linn.-A critical review. Global Journal of Research on Medicinal Plants \& Indigenous Medicine, 6(9), 100-113. Obtido em: https://www.proquest.com/openview/15flb12d7df1867e3b4d14bf62bfee20/1?pq-origsite=gscholar\&cbl=2026661

Ribeiro, J. E. L. da S. (Org.). (1999). Flora da Reserva Ducke: Guia de identificação das plantas vasculares de uma floresta de terra-firme na Amazônia Central. Manaus, Brasil: INPA DFID.

Rocha Neto, O. G., Lameira, O. A., Vieigas, I. J. M., \& Carvalho, C. R. J. (1997). Estudos agronômicos e fisiológicos visando a propagação e domesticação da quina (Quassia amara L.) (Programa de Matérias-Prirnas/Subprojeto 07.0.95.005.03.). EMBRAPA- CPATUl.

Roncon, C., Biesdorf de Almeida, C., Klein, T., Palazzo de Mello, J., \& Audi, E. (2011). Anxiolytic effects of a semipurified constituent of guaraná seeds on rats in the elevated T-Maze test. Planta Medica, 77(03), 236-241. 10.1055/s-0030-1250315

Roncon, C. M. (2009). Effect of semi-purified constituent from guaraná seeds [Paullinia cupana var. Sorbilis (Mart.) Ducke] on performance of rats in elevated T maze [Dissertação de Mestrado]. Universidade Estadual de Maringá.

Rossetti, V., Lombard, A., Sancin, P., Buffa, M., \& Menghini, A. (1984). Composition of Gentiana lutea L. dried roots harvested at different altitudes. Plant Med Phytother, 18, 15-23.

Schenkel, E. P., Gosmann, G., \& Petrovick, P. R. (2004). Produtos de origem vegetal e o desenvolvimento de medicamentos. In C. M. O. Simões, E. P. Schenkel, G. Gosmann, J. C. P. Mello, L. A. Mentz, \& P. R. Petrovick, Farmacognosia da Planta ao Medicamento (5a ed,), 1102. Editora da UFSC.

Shah, C. (2009). Textbook of pharmacognosy and phytochemistry (p. 273-274). Elsevier.

Sharma, V., Kaushik, R., Majee, C., \& Jain, J. (2021). Natural products against coronaviruses. International Journal of Pharmaceutical Sciences and Research, 4143-4150. 10.13040/IJPSR.0975-8232.12(8).4143-50

Silva, R. da. (1925). Plantas medicinais brasileiras: Estudo botânico e pharmacognóstico-Muirapuama. Rev Bras Med Pharm, 1(1), $37-41$.

Silva, N. C. S., Vítor, A. M., da Silva Bessa, H. H., \& Barros, R. M. S. (2017). A utilização de plantas medicinais e fitoterápicos em prol da saúde. Única cadernos acadêmicos, 3(1).

Siqueira, I. R., Fochesatto, C., Torres, I. L. S., da Silva, A. L., Nunes, D. S., Elisabetsky, E., \& Netto, C. A. (2007). Antioxidant activities of Ptychopetalum olacoides ("muirapuama") in mice brain. Phytomedicine, 14(11), 763-769. 10.1016/j.phymed.2006.12.007

Siqueira, I. R., Lara, D. R., Silva, D., Gaieski, F. S., Nunes, D. S., \& Elisabetsky, E. (1998). Psychopharmacological properties of Ptychopetalum olacoides Bentham (Olacaceae). Pharmaceutical Biology, 36(5), 327-334. 10.1076/phbi.36.5.327.4657

Steinmetz, E. (1971). Muira Puama ('Potenzholz'). Quarterly Journal of Crude Drug Research, 11(3), 1787-1789. 10.3109/13880207109082398

SUFRAMA. (2013). Potencialidades estudo de viabilidade econômica: Guaraná. In Superintendência da zona franca de Manaus. Instituto superior de administração e economia ISAE/Fundação Getúlio Vargas (FGV). Obtido em: http://www.suframa.gov.br/publicacoes/proj_pot_regionais/sumario/guarana.pdf

Tang, W., Kubo, M., Harada, K., Hioki, H., \& Fukuyama, Y. (2009). Novel NGF-potentiating diterpenoids from a brazilian medicinal plant, Ptychopetalum olacoides. Bioorganic \& Medicinal Chemistry Letters, 19(3), 882-886. 10.1016/j.bmcl.2008.11.100

Tfouni, S. A. V., Camargo, M. C. R., Vitorino, S. H. P., Menegário, T. F., \& Toledo, M. C. de F. (2007). Contribuição do guaraná em pó (Paullinia cupana) como fonte de cafeína na dieta. Revista de Nutrição, 20(1), 63-68. 10.1590/S1415-52732007000100007 
Toma, W., Gracioso, J. de S., Hiruma-Lima, C., Andrade, F. de, Vilegas, W., \& Brito, A. S. (2003). Evaluation of the analgesic and antiedematogenic activities of Quassia amara bark extract. Journal of Ethnopharmacology, 85(1), 19-23. 10.1016/S0378-8741(02)00334-3

Toyota, A. (1979). Studies of brazilian crude drugs .1. Muira-puama. Shoyakugaku Zasshi, 33(2), 57-64.

Tricaud, S., Pinton, F., \& Pereira, H. dos S. (2016). Saberes e práticas locais dos produtores de guaraná (Paullinia cupana Kunth var. sorbilis) do médio Amazonas: Duas organizações locais frente à inovação. Boletim do Museu Paraense Emílio Goeldi. Ciências Humanas, 11(1), 33-53. $10.1590 / 1981.81222016000100004$

Velasco, M., Maciel, C., Sarruf, F., Consiglieri, V., Kaneko, T., \& Baby, A. (2008). Desenvolvimento e teste preliminar da estabilidade de formulações cosméticas acrescidas de extrato comercial de Trichilia catigua Adr. Juss (e) Ptychopetalum olacoides Bentham. Revista de Ciências Farmacêuticas Básica e Aplicada, 29(2). Obtido em: http://rcfba.fcfar.unesp.br/index.php/ojs/article/view/485/483

Velayutham, P., Babu, A., \& Liu, D. (2008). Green tea catechins and cardiovascular health: An update. Current medicinal chemistry, 15(18), 1840. Obtido em: https://www.ncbi.nlm.nih.gov/pmc/articles/PMC2748751/

Verotta, L. (1985). Isolation and HPLC determination of the active principles of Rosmarinus officinalis and Gentiana lutea. Fitoterapia, 56, 25-29.

Vicentini, A., \& Rossi, L. (1999). Olacaceae. In J. E. L. S. Ribeiro, M. J. G. Hopkins, A. Vicentini, C. A. Sothers, M. A. S. Costa, J. M. Brito, M. A. D. Souza, L. H. P. Martins, L. G. Lohmann, P. A. C. L. Assunção, E. C. Pereira, C. F. Silva, M. R. Mesquita, \& L. Procópio, Flora da Reserva Ducke (p. 799). Manaus, Brasil: INPA; DFID.

Webb, G. P. (2008). Dietary Supplements and Functional Foods. Bridgewater, Willey.

Weigel, G. (1907). The wood and root of muira-puama. Pharm Cent, 190(49), 139-141.

Wu, S., Ning, Y., Zhao, Y., Sun, W., Thorimbert, S., Dechoux, L., Sollogoub, M., \& Zhang, Y. (2016). Research progress of natural product gentiopicroside—A secoiridoid compound. Mini-Reviews in Medicinal Chemistry, 17(1), 62-77. 10.2174/1389557516666160624124127

Yamaguchi, K. K. de L., \& Souza, A. de O. (2020). Antioxidant, hypoglycemic and neuroprotective activities of extracts from fruits native to the amazon region: A review. Biotechnology Journal International, 9-31. 10.9734/bji/2020/v24i630119

Yamaguti-Sasaki, E., Ito, L., Canteli, V., Ushirobira, T., Ueda-Nakamura, T., Filho, B., Nakamura, C., \& Palazzo de Mello, J. (2007). Antioxidant capacity and in vitro prevention of dental plaque formation by extracts and condensed tannins of Paullinia cupana. Molecules, 12(8), 1950-1963. 10.3390/12081950

Yonekura, L., Martins, C. A., Sampaio, G. R., Monteiro, M. P., César, L. A. M., Mioto, B. M., Mori, C. S., Mendes, T. M. N., Ribeiro, M. L., Arçari, D. P., \& Torres, E. A. F. da S. (2016). Bioavailability of catechins from guaraná (Paullinia cupana) and its effect on antioxidant enzymes and other oxidative stress markers in healthy human subjects. Food \& Function, 7(7), 2970-2978. 10.1039/C6FO00513F 